\title{
ANALISIS BAHASA PIJIN PADA IKLAN PERTELEVISIAN INDONESIA
}

\author{
Ariyana \\ Universitas Muhammadiyah Tangerang \\ Jln. Perintis Kemerdekaan I No.1, Babakan, Kec. Tangerang, Kota Tangerang, Indonesia \\ Email: ariyana.mpd.@gmail.com
}

\begin{abstract}
Abstrak
Tujuan dari penelitian ini adalah untuk mendeskripsikan kata dan kalimat sebagai bahasa Pijin pada iklan pertelevisian Indonesia. Penelitian ini menggunakan pendekatan kualitatif. Metode penelitian dalam penelitian ini adalah metode analisis isi, terutama dalam menganalisis bahasa Pijin dalam iklan televisi Indonesia. Teknik pengumpulan data menggunakan teknik dokumentasi, observasi, dan catat. Teknik analisis data Sumber data yang terkait dengan penelitian bahasa Pijin dalam siaran TV Indonesia, yaitu: Chocolathos, Go Jek, Fulvita Selasih, Open Lapak, Axis, dan Tickets.com. Teknik analisis data dengan cara: reduksi data, penyajian data, dan verifikasi. Uji keabsahan data dilakukan dengan triangulasi dan validasi pakar. Dari hasil penelitian, penggunaan Pijin dalam iklan di televisi Indonesia, terdapat enam kosa kata yang berasal dari bahasa Pijin di enam iklan, yaitu: bete, emejing, syantik, okay, lemot, dan chayank. Bahasa Pijin dapat dilihat dari struktur bahasa yang sederhana dibandingkan dengan bahasa sumber, yang mana bahasa Pijin dapat dilihat dalam aspek tata bahasa dan pengucapan.
\end{abstract}

Kata kunci: Bahasa Pijin, Iklan Televisi

\section{AN ANALYSIS OF PIDGIN LANGUAGE ON TELEVISION ADVERTISEMENT IN INDONESIA}

\begin{abstract}
The purpose of this study was to describe words and sentences as Pijin in Indonesian television advertisements. This study uses a qualitative approach. The research method in this study is the method of content analysis, especially in analyzing Pijin in Indonesian television advertisements. Data collection techniques use documentation, observation, and note taking techniques. Data sources related to Pijin research in Indonesian TV broadcasts, namely: Chocolathos, Go Jek, Fulvita Selasih, Open Lapak, Axis, and Tickets.com. Data analysis techniques by: data reduction, data presentation, and verification. The validity test of the data is done by expert triangulation and validation. From the results of the study, the use of Pijin in Indonesian television advertisements, there are six vocabulary words from Pijin in six advertisements, namely: bete, emejing, syantik, okay, lemot, and chayank. Pijin language can be seen from a simple language structure compared to the source language, which Pijin language can be seen in aspects of grammar and pronunciation.
\end{abstract}

Keywords: Pidgin Language, Television Advertisement 


\section{A. Pendahuluan}

Dalam kehidupan bermasyarakat, manusia tidak terlepas dari penggunaan bahasa di lingkungannya untuk berkomunikasi. Proses komunikasi ini mengalami keragaman dan kevariasian bahasa yang digunakan, bukan saja disebabkan oleh penuturnya yang tidak homogen, tetapi juga karena kegiatan interaksi sosial yang mereka lakukan sangat beragam (Chaer \& Agustina, 2010:62). Hal ini menunjukkan bahwa bahasa benar-benar bersifat arbitrer dan dinamis. Perkembangan bahasa mengalami variasi yang unik, khususnya berdasarkan faktor sosiologis. Variasi bahasa berdasarkan faktor sosiologis dimaknai bahwa variasi bahasa tidak hanya terbatas pada struktur internal bahasa, tetapi juga berdasarkan faktor sejarahnya, kaitannya dengan sistem linguistik lain, dan pewarisan dari generasi ke generasi berikutnya.

Variasi bahasa berdasarkan faktor sosiologis yang unik dalam pembentukannya adalah bahasa Pijin. Bahasa ini, dalam pembentukannya memiliki ciri khas tersendiri dibandingkan dengan variasi bahasa lainnya, seperti bahasa standar, vernacular, klasik, dialek, dan bahasa lainnya. Secara umum bahasa Pijin, dalam pembentukannya tidak memiliki ciri vitalitas, standardisasi, otonomi, dan historisitas.

Bahasa merupakan suatu ungkapan yang mengandung maksud untuk menyampaikan sesuatu kepada orang lain. Sesuatu yang dimaksudkan oleh pembicara bisa dipahami dan dimengerti oleh pendengar atau lawan bicara melalui bahasa yang diungkapkan. Chaer \& Agustina (2010:14) menjelaskan bahwa fungsi utama bahasa adalah sebagai alat komunikasi. Hal ini sejalan fungsi umum bahasa adalah sebagai alat komunikasi sosial. Sosiolinguistik memandang bahasa sebagai tingkah laku sosial (sosial behavior) yang dipakai dalam komunikasi sosial.

Bahasa merupakan alat utama untuk berkomunikasi dalam kehidupan manusia, baik secara individu, maupun kolektif sosial. Bahasa sebagai suatu sistem lambang arbitrer yang menggunakan suatu masyarakat untuk bekerja sama, berinteraksi, dan mengidentifikasikan diri. Pengalaman sehari-hari menunjukkan bahwa ragam lisan lebih banyak daripada ragam tulis. Ragam lisan berbeda dengan ragam tulis karena peserta percakapan mengucapkan tuturan 
dengan tekanan, nada, irama, jeda, atau lagu tertentu untuk memperjelas makna dan maksud tuturan. Selain itu, kalimat yang digunakan oleh peserta percakapan tidak selalu merupakan kalimat lengkap.

Bahasa adalah sistem yang terbentuk dari isyarat suara yang telah disepakati, yang ditandai dengan struktur yang saling tergantung, kreativitas, penempatan, dualitas, dan penyebaran budaya. Menurut Chaer \& Agustina (2010) bahasa terdiri dari sejumlah dialek, dan setiap dialek terdiri dari sejumlah idiolek, namun dua buah dialek secara linguitik adalah bahasa yang dapat saling dimengerti.

Bahasa Pijin (Pidgin) adalah sebuah bahasa yang muncul sebagai hasil interaksi antara dua kelompok yang berbicara dengan bahasa yang berbeda dan tidak mengerti apa yang dibicarakan satu sama lain, sehingga mereka menggunakan apa yang dinamakan dengan pidgin tersebut untuk berkomunikasi. Disituasi lain, ada beberapa orang dengan latar belakang bahasa yang berbeda yang harus berkomunikasi dengan yang lainnya, tetapi dengan satu bahasa yang paling dominan digunakan (Wardaugh \& Fuller, 2015:117). Kajian ini juga dijelaskan oleh Holmes (2013:85) bahwa Pijinn ialah bahasa yang bukan dari penutur asli. Pijin mengembangkan makna dari sebuah komunikasi di antara orang-orang yang bukan sebagai pengguna bahasa aslinya. Pijin juga adalah sebuah bahasa yang muncul sebagai hasil interaksi antara dua kelompok yang berbicara dengan bahasa yang berbeda dan tidak mengerti apa yang dibicarakan satu sama lain, sehingga mereka menggunakan apa yang dinamakan dengan Pijin ini untuk berkomunikasi. Dengan kata lain Pijin adalah bahasa yang dihasilkan oleh sebuah kelompok orang yang tidak memiliki bahasa yang sama, kemudian berkembang sebagai alat komunikasi untuk perdagangan, tetapi bahasa ini tidak memiliki penutur asli.

Biasanya bahasa Pijin terjadi di kota-kota pelabuhan tempat bertemunya pedagang dan pelaut dari berbagai bangsa dan atau suku bangsa yang berlainan dengan bahasa ibunya. Pijin terbentuk sebagai bahasa campuran dari bahasa pelaut dan pedagang tersebut dan hanya digunakan sebagai alat komunikasi di antara mereka yang berbahasa ibu yang berbeda. Oleh sebab itu, mengapa bahasa Pijin tidak memiliki ciri vitalitas, standardisasi, otonomi, dan historisitas. 
Vitalitas atau keterpakaian merupakan pemakaian sistem linguistik oleh satu masyarakat penutur asli yang tidak terisolasi atau terkait dengan masih ada tidaknya penutur asli yang menggunakan bahasa tersebut. Standardisasi atau pembakuan berkaitan dengan adanya kodefikasi dan penerimaan terhadap bahasa oleh masyarakat pemakai bahasa itu akan seperangkat kaidah atau norma yang menentukan pemakaian bahasa yang benar. Otonomi berarti sebuah sistem bahasa memiliki kemandirian sistem yang tidak berkaitan dengan bahasa lain. Kemudian, historisitas atau kesejarahan terjadi pada sebuah sistem linguistik yang dianggap memiliki historisitas kalau diketahui atau dipercaya sebagai hasil perkembangan yang normal pada masa yang lalu. Faktor historisitas ini mempersoalkan apakah sistem linguistik itu tumbuh melalui pemakaian oleh kelompok etnik atau sosial tertentu atau tidak. Para penutur suatu sistem bahasa yang memiliki unsur kesejarahan mempunyai kemungkinan untuk menguasai unsur kesejarahan. Bahasa Pijin, sama sekali tidak memiliki ciri vitalitas, standardisasi, otonomi, dan historisitas sehingga benar-benar tidak memiliki penuturnya lagi.

Wardhaugh dalam Sulaeman (2018) mengemukakan bahasa Pijin sebagai berikut:

"A pidgin is a language with no native speakers: it is no one"s first language but is a contact language. That is, it is the product of a multilingual situation in which those who wish to communicate must find or improvise a simple language system that will enable them to do so".

Dari kutipan yang disampaikan Wardhaugh mengandung makna bahwa pijin (pidgin) adalah sebuah bahasa yang tidak memiliki penutur asli: bahasa ini bukan bahasa pertama seseorang, melainkan bahasa pergaulan (contact language), dan merupakan hasil dari situasi multibahasa, yang mana seseorang yang hendak berkomunikasi dengan orang lain harus menemukan cara atau mengembangkan kode-kode sederhana. Pijin juga merupakan sebuah bahasa yang muncul sebagai hasil interaksi antara dua kelompok yang berbicara dengan bahasa yang berbeda dan tidak mengerti apa yang dibicarakan satu sama lain, sehingga mereka menggunakan apa yang dinamakan dengan pijin ini untuk berkomunikasi. Misalnya, pedagang asongan di kawasan Tanah Lot bertutur 
dengan wisatawan asing dalam bahasa Inggris pijin. Bahasa Inggris digunakan sebagai dasar dan lafalnya disesuaikan dengan lidah Indonesia, contohnya:

a. peri cip (very cheap) = sangat murah

b. paip (five) $=$ lima

C. masas (massage) $=$ pesan

d. tosen (thousand) $=$ seribu

e. many-many different with art shop (the price is much different from the price given in the art shop) = harganya banyak beda dengan di toko.

Pijin berkembang sebagai alat komunikasi antara orang-orang yang tidak memiliki bahasa yang sama. Dengan demikian, pijin bukanlah bahasa ibu seseorang. Pijin tampaknya sangat mungkin muncul ketika dua kelompok dengan bahasa yang berbeda berkomunikasi dalam situasi di mana ada juga bahasa dominan ketiga. Di perkebunan budak Karibia di abad XVII dan XVIII, orang Afrika Barat sengaja dipisahkan dari orang lain yang menggunakan bahasa yang sama, sehingga dapat mengurangi risiko rencana mereka untuk melarikan diri atau memberontak. Dalam rangka untuk berkomunikasi satu sama lain, serta dengan pengawas mereka, mereka mengembangkan pijin berdasarkan bahasa bos perkebunan serta bahasa mereka sendiri.

Wardhaugh dan Fuller dalam Sulaeman (2018) mendefinisikan istilah lain yang digunakan para ahli bahasa (linguist) dalam mendefinisikan pijin dan kreol yakni kata "superstrate" dan "substrate" untuk merujuk pada perbedaan peran bahasa dalam perkembangan bahasa pergaulan (contact language). Bahasa superstrate (biasanya hanya satu) adalah bahasa yang secara sosial, ekonomi, dan politik, bahasa yang dominan dalam kontek multibahasa yang mana pijin dan kreol berkembang. Superstrate language juga biasanya merupakan bahasa yang menyediakan kosakata untuk pijin dan kreol, dalam hal ini juga disebut lexifier language. Meskipun secara sosial dominan kita juga mengakui bahwa variasi superstrate language dilisankan dalam konteks tertentu tidak selalu dianggap standar.

Kemudian, Kushartati (dalam Sulaeman, 2018) juga menjelaskan bahwa pijin merupakan ragam bahasa yang tidak memiliki penutur asli. Biasanya ragam 
bahasa ini ditemukan di negara-negara dunia ketiga yang dulunya merupakan daerah jajahan atau koloni. Ragam bahasa ini tumbuh karena ada dua pihak yang ingin berkomunikasi satu sama lain, tetapi sangat berbeda ragam bahasanya. Mereka tidak menggunakan bahasa ketiga sebagai bahasa perantara, tetapi mereka menggabungkan dua bahasa mereka. Ragam bahasa ini biasanya digunakan sebagai alat komunikasi antar imigran dan orang-orang lokal atau penduduk asli sehingga keduanya dapat saling mengerti tanpa harus mempelajari bahasa dari kelompok lain. Ragam bahasa ini juga muncul sebagai reaksi atau respons mereka terhadap perubahan politik dan sosial di negara mereka.

Bahasa pijin awalnya muncul melalui proses pembelajaran bahasa kedua karena desakan keadaan, misanya di perkebunan, di mana para budak dari berbagai wilayah di Afrika dipekerjakan dalam satu tempat dan mereka harus saling berkomunikasi dengan sesama mereka di samping dengan pihak yang berkuasa. Variasi bahasa muncul dari proses fosilisasi dan konvensionalisasi. Jumlah bahasa pijin lebih dari 100 di dunia. Kebanyakan pijin ini dipengaruhi oleh bahasa-bahasa Eropa, pada umumnya Inggris, Spanyol. dan Prancis. Contoh ragam pijin yang paling terkenal adalah pijin Melanesia, seperti Tok Pisin di Papua New Guinea yang sekarang sudah beralih menjadi kreol, Bislama di Vanuatu, dan pijin di Solomon Island. Bahasa Pijin ini dipengaruhi bahasa Eropa seperti Inggris, Jerman, Portugis, dan Melayu.

Dunia pergaulan di Indonesia memiliki kebebasan tidak hanya dalam kehidupan sehari-hari yang ditampilkan, tetapi juga kebebasan dalam hal berkomunikasi dan berinteraksi terhadapa penutur dan lawan tutur. Zaman milenial saat ini banyak peggunaan kata-kata tidak sesuai pada konteks yang sebenarnya di lingkungan pendidikan sekolah maupun kampus. Variasi bahasa yang diduga mengalami bahasa Pijin ialah terdapat pada media iklan. Menurut Palupi \& Pambudi (2006), iklan atau dalam bahasa Indonesia umumnya pariwara adalah semua bentuk pesan promosi benda seperti barang, jasa, tempat usaha, dan ide yang disampaikan melalui media dengan biaya sponsor dan ditunjukan kepada sebagian besar masyarakat.

Iklan sebagai sarana berekspresi yang tidak ada aturan baku mengenai bahasa sehingga bahasa yang harusnya menggunakan bahasa yang baik dan 
benar menjadi bahasa suka-suka atau bahasa pijin yang tercipta karena memudahkan untuk berkomunikasi. Kajian terhadap iklan masih sebatas pada kajian terhadap unsur variasi linguitik saja belum melihat sebagai kajian bahasa Pijin. Untuk itu, dalam pemebahasan ini akan difokuskan untuk menjawab tentang "Bagaimanakah karakteristik bahasa Pijin pada iklan pertelevisian Indonesia? Sehingga diharapkan memberikan pemahaman bahwa bahasa iklan juga mengalami variasi yang diakibatkan faktor sosiologis terutama diakibatkan oleh kebutuhan-kebutuhan hidup dalam masyarakat yang penuturnya dari jenis profesi yang sama atau berbeda, tetapi dengan penutur yang berasal dari daerah yang berbeda.

\section{B. Metode Penelitian}

Penelitian ini menggunakan pendekatan kualitatif dengan tujuan mampu mendeskripsikan bagaimana bahasa Pijin pada iklan di televisi Indonesia. Metode penelitian menggunakan metode analis isi, khususnya dalam menganalisis bahasa Pijin dalam iklan di televisi Indonesia. Menurut Hanafi (2011) metode penelitian kualitatif adalah "penelitian yang ingin mencari makna kontekstual secara menyeluruh berdasarkan fakta-fakta (tindakan, ucapan, sikap, dsb.) yang dilakukan subjek penelitian dalam latar alamiah secara emic, menurut yang dikonstruk objek penelitian untuk membangun teori (nomotetik, mencari hukum keberlakuan umum)".

Analisis isi merupakan suatu metode yang teknik penelitiannya dilakukan dengan membuat inferensi secara kontekstual. Jadi, pesan-pesan komunikasi dapat dipahami secara utuh (Sulaeman, 2017). Isi dalam metode analisis isi terdiri atas dua macam, yaitu isi laten dan isi komunikasi. Isi laten adalah isi yang terkandung dalam dokumen dan naskah, sedangkan isi komunikasi adalah pesan yang terkandung sebagai akibat komunikasi yang terjadi. Tiga tujuan utama penggunaan analisis isi yaitu untuk mendeskripsikan data, menguji hipotesis dan membuat inferensi.

Sumber data terkait dengan penelitian ini adalah bahasa Pijin dalam siaran TV Indonesia, yaitu iklan Chocolathos, Go Jek, Fulvita Selasih, Buka Lapak, Axis, dan Tiket.com. Sedangkan jenis data penelitian kuliatatif bahasa ini 
dikelompokkan menjadi data primer dan sekunder. Data primer adalah data yang didapat secara langsung dari sumber utama itu sendiri. Data primer dalam penelitian ini adalah iklan Chocolathos, Go Jek, Fulvita Selasih, Buka Lapak, Axis, Tiket.com. Data sekunder adalah data yang diperoleh secara tidak langsung atau lewat perantara, tetapi berstandar pada kategori atau parameter yang menjadi rujukan. Data sekunder dalam penelitian ini adalah buku-buku dan jurnal-jurnal referensi yang terkait dalam objek penelitian.

Teknik pengumpulan data yang digunakan dalam penelitian ini dilakukan dengan teknik dokumentasi, observasi, dan catat. Teknik observasi digunakan untuk melihat ulang suatu objek, yakni berupa tuturan dalam iklan yang sedang diteliti. Sedangkan teknik catat digunakan untuk mencatat tuturan yang terjadi dan untuk meminimalisir kehilangan data, apabila dengan cara mengamati kurang jelas maka dapat diperjelas dengan catatan dan data diperoleh dengan mengkombinasikan kedua teknik tersebut. Dalam penelitian yang penulis lakukan ini adalah ingin mengetahui tuturan bahasa pidgin dalam iklan di televisi Indonesia melalui teknik observasi atau pengamatan.

Observasi adalah mengadakan pengamatan secara langsung, observasi dapat dilakukan dengan tes, kuesioner, ragam gambar, dan rekaman suara. Pedoman observasi berisi sebuah daftar jenis kegiatan yang mungkin timbul dan akan diamati. Pedoman observasi atau pengamatan diperlukan terutama jika peneliti menerapkan pengamatan terfokus dalam proses pengumpulan data. Dalam pengamatan terfokus peneliti memusatkan perhatian hanya pada beberapa aspek perilaku atau fenomena yang menjadi objek sasarannya.

Menurut Siswantoro dalam Sulaeman (2017) instrumen adalah alat yang dipergunakan untuk mengumpulkan data. Jadi dalam penelitian kualitatif bahasa, yang menjadi intrumen atau alat penelitian adalah peneliti itu sendiri. Mengetahui posisi penelitian sebagai alat penelitian atau instrument terkait maka penelitian bahasa ini berorientasi kepada video, bukan kepada sekelompok individu yang menerima suatu perlakuan tertentu. Namun, untuk membantu peneliti dalam menganalisis data pada penelitian ini, peneliti menggunakan alat bantu berupa tabel. Keberhasilan penelitian ditentukan oleh instrumen yang digunakan, karena data yang diperoleh melalui instrumen. Alat pengambilan harus dirancang dan 
dibuat sedemikian rupa sebagai yang menghasilkan data empris. Instrumen penelitian ini dibantu dengan observasi atau pengamatan, atau nontes dibuat oleh peneliti itu sendiri. Sugiyono (2015), mengatakan bahwa "instrumen penelitian digunakan untuk mengukur nilai variabel yang diteliti”. Agar lebih mudah dalam pengumpulan data maka peneliti membuat beberapa bentuk tabel analisis.

Dalam penelitian kualitatif, data yang diperoleh dari berbagai sumber dengan menggunakan teknik pengumpulan data yang bermacam-macam (triangulasi), dan dilakukan secara terus-menerus sampai datanya jenuh. Analisis data merupakan salah satu cara mencari, mengumpulkan dan menyusun data secara sistematis yang didapatkan melalui hasil wawancara dan observasi di lapangan yang menghasilkan sebuah data baru yang relevan dan berdasarkan fakta.

Dalam penelitian ini peneliti menggunakan teknik analisis data menggunakan model Miles and Huberman (Sugiyono, 2015:337) berupa rancangan analisis data yang dilakukan secara interaktif dan berlangsung secara terus-menerus sampai tuntas, sehingga datanya sudah jenuh. Aktivitas dalam analasis data, yaitu reduksi data, penyajian data, dan verifikasi (Sugiyono, 2015:337). Mereduksi data yaitu merangkum, memilih hal-hal yang pokok, memfokuskan pada hal-hal yang penting, dicari tema dan polanya, serta membuang yang tidak perlu. Data-data yang dipilih hanya data yang berkaitan dengan masalah yang akan dianalisis. Data yang dipilih dalam penelitian ini tentang bahasa Pijin dalam iklan pertelevisian Indonesia. Penyajian data ( data display), dalam penelitian kualitatif, penyajian data bisa dilakukan dalam bentuk uraian singkat, bagan, hubungan antar kategori, flowchart dan sejenisnya. Dalam hal ini yang paling sering digunakan untuk menyajikan data dalam penelitian kualitatif adalah dengan teks yang bersifat naratif. Setelah dilakukan pengumpulan data, selanjutnya dilakukan penyajian data. Pada langkah ini data disajikan dengan menyiapkan rekaman atau video yang telah ditranskipkan ke dalam bentuk tulisan. Langkah terakhir yaitu verifikasi (conclusion drawing atau verivication). Pada tahapan ini dibuat kesimpulan tentang hasil data yang diperoleh sejak awal penelitian. Kesimpulan ini masih memerlukan adanya verifikasi. 


\section{Hasil Penelitian dan Pembahasan}

\section{Hasil Penelitian}

Dalam penelitian bahasa Pijin, peneliti menggunakan iklan di televisi Indonesia sebagai objek observasi. adapun hasil yang didapat peneliti temukan dapat ditunjukkan pada tabel 1. di bawah ini.

Tabel 1. Penggunaan Bahasa Pidgin dalam Pergaulan Remaja

\begin{tabular}{cccl}
\hline No. & Pidgin & Padanan Bahasa Indonesia & \multicolumn{1}{c}{ Arti Kata Menurut KBBI } \\
\hline 1 & Bete & Bosan & Tidak suka lagi \\
\hline 2 & Emejing & Menakjubkan & $\begin{array}{l}\text { Menimbulkan takjub atau } \\
\text { mengagumkan }\end{array}$ \\
\hline 3 & Syantik & Cantik & $\begin{array}{l}\text { Indah dalam bentuk dan } \\
\text { buatannya }\end{array}$ \\
\hline 4 & Okay & Oke & $\begin{array}{l}\text { Kata untuk menyatakan } \\
\text { setuju }\end{array}$ \\
\hline 5 & Lemot & Lambat & $\begin{array}{l}\text { Perlahan-lahan gerakannya, } \\
\text { jalannya dan sebagainya }\end{array}$ \\
\hline 6 & Chayank & Sayang & Amat Suka kepada sesuatu \\
\hline
\end{tabular}

Berdasarkan tabel 1, maka dapat dijelaskan maknanya sebagai berikut.

a. Bete (Bt)

Kata bete merupakan singkatan dari boring today, boring time, boring total atau bosan total. Intinya kata bete tersebut digunakan apabila seseorang sedang bosan. Kata tersebut terdapat pada kalimat iklan chocolatos "bete larutkan semua masalah kamu dengan chocolatos drink ". Padanan bahasa Indonesia dari kata bete searti dengan kata bosan dan memiliki makna dalam kamus besar bahasa Indonesia adalah tidak suka lagi.

\section{b. Emejing}

Kata emejing digunakan sebagai kata tercengang atau terkaget dengan hal yang luar biasa. Kata tersebut terdapat pada kalimat di dalam iklan axis "Raburabu 000 emejing, rabu rawit, rabu wajib irit ". Padanan bahasa Indonesia dari kata emejing searti dengan kata menakjubkan dan memiliki makna dalam kamus besar bahasa Indonesia adalah menimbulkan rasa takjub dan mengagumkan. 
C. Syantik

Kata syantik digunakan sebagai kata untuk memuji diri sendiri maupun orang lain dalam segi fisik. Kata tersebut terdapat pada kalimat di dalam iklan full vita selasih "selasihnya syantik". Padanan bahasa Indonesia dari kata syantik searti dengan kata cantik dan memiliki makna dalam kamus besar bahasa Indonesia adalah indah dalam bentuk dan buatannya.

\section{d. Okay}

Kata okay digunakan sebagai kata untuk memberikan persetujuan dalam hal yang telah dijelaskan sebelumnya. Kata tersebut terdapat pada kalimat di dalam iklan buka lapak "dinego aja say, pasti bisa say, dinego sampai okay". Padanan bahasa indonesia dari kata okay searti dengan kata oke dan memiliki makna dalam kamus besar bahasa Indonesia adalah kata untuk menyatakan setuju.

\section{e. Lemot}

Kata lemot digunakan sebagai kata untuk menyatakan sesuatu hal yang dianggap dapat menghambat prosesnya. Kata tersebut terdapat pada kalimat di dalam iklan Andromex M3z "HP kita juga lemot nih". Padanan bahasa Indonesia dari kata lemot searti dengan kata lambat dan memiliki makna dalam kamus besar bahasa Indonesia adalah perlahan-lahan gerakannya, jalannya dan sebagainya.

\section{f. Chayank}

Kata chayank digunakan sebagai kata untuk mengungkapkan perasaan suka yang berlebih terhadap pasangan dan hal lainnya. Kata tersebut terdapat pada kalimat di dalam iklan Go Jek " Hai chayank sory baru isi pulsa”. Padanan bahasa Indonesia dari kata chayank searti dengan kata sayang dan memiliki makna dalam kamus besar bahasa Indonesia adalah amat suka kepada sesuatu.

\section{Pembahasan}

Pemakaian bahasa Pijin dalam iklan di televisi indonesia ditemukan enam kosakata bahasa Pijin dalam iklan Chocolathos, Go Jek, Fulvita Selasih, Open Lapak, Axis, dan Tickets.com, yaitu kosakata bete, emejing, syantik, okay, lemot, 
dan chayank. Bahasa Pijin dapat dilihat dari struktur bahasa yang sederhana dibandingkan dengan bahasa sumber, yang mana bahasa Pijin dapat dilihat dalam aspek tata bahasa dan pelafalannya.

Berdasarkan hasil penelitian tersebut, terlihat bahwa bahasa Indonesia dapat berkembang karena adanya bahasa Pijin yang digunakan oleh masyarakat secara meluas. Bahasa Pijin yang pada mulanya hanya berkembang di dalam komunitas tertentu, secara perlahan akan menyebar di tengah-tengah masyarakat dan secara tidak sadar akan menjadi bagian dari bahasa mereka sendiri. Sebagaimana penelitian yang dilakukan oleh Sukesti (2015) bahwa bahasa Indonesia juga berkembang dari bahasa Melayu yang digunakan di tengah-tengah masyarakat. Bahasa Melayu yang pada mulanya digunakan oleh suatu kelompok masyarakat tertentu menyebar melalui komunikasi dan interaksi yang terjadi antar kelompok masyarakat di suatu daerah.

Hal ini senada dengan pendapat Beratha (1999) bahwa bahasa Indonesia berkembang akibat adanya berbagai macam variasi bahasa yang digunakan oleh masyarakat, salah satunya adalah bahasa Pijin. Namun, masyarakat Indonesia harus mampu menyeleksi bahasa Pijin yang digunakan, terutama tingkat kesantunan atau kesopanan atau keberterimaan bahasa Pijin dalam budaya Indonesia (Pastika, 2012). Menurut Pastika (2012), tidak semua bahasa Pijin dapat digunakan di dalam berkomunikasi sehari-hari, karena ada beberapa kata yang tabu atau tidak pantas untuk digunakan yang bertolak belakang dengan budaya Indonesia.

Di dalam penelitian ini, perkembangan bahasa terjadi akibat adanya iklan yang disajikan di berbagai stasiun televisi di Indonesia. Sebagaimana yang dikatakan oleh Suhardi (2009) bahwa perkembangan bahasa yang terjadi di tengah-tengah masyarakat tidak bisa dibatasi, karena terbukanya komunikasi yang ada di tengah-tengah masyarakat. Misalnya, pertemuan resmi, media elektronik, media luar negeri, dan lain-lain. Semuanya terbuka dan dapat diakses oleh masyarakat luas.

Dengan adanya bahasa Pijin, maka akan terjadi percampuran antara bahasa penutur asli dengan bahasa Pijin tersebut (Choi \& Chong, 2017). Pemakaian bahasa Pijin dalam bahasa iklan di TV Indonesia merupakan 
fenomena yang menarik untuk dikaji dari perspektif sosiolinguistik. Masyarakat Indonesia sebagian besar dalam masyarakat yang dwibahasa. Adanya dwibahasaan tersebut dapat memunculkan pemakaian bahasa yang bervariasi dalam masyarakat.

\section{Simpulan}

Hasil penelitian menunjukkan bahwa penggunaan bahasa Pijin dalam iklan di televisi Indonesia, terdapat enam kosakata yang berasal iklan Chocolathos, Go Jek, Fulvita Selasih, Open Lapak, Axis, dan Tickets.com, yaitu kosakata bete, emejing, syantik, okay, lemot, dan chayank. Bahasa Pijin dapat dilihat dari struktur bahasa yang sederhana dibandingkan dengan bahasa sumber, yang mana bahasa Pijin dapat dilihat dalam aspek tata bahasa dan pengucapan.

Banyaknya iklan di televisi yang menggunakan bahasa Pijin, hal ini bisa berdampak baik untuk variasi bahasa yang ada di Indonesia, karena menambah variasi bahasa baru yang ada di Indonesia, tetapi sangat berdampak buruk terhadap keaslian bahasa sumbernya, karena bahasa Pijin adalah bahasa baru, yang terbentuk dari dua bahasa, yang membuat bentuk bahasa itu tidak lagi sesuai dengan struktur bahasa aslinya, sehingga dapat menghilangkan bahasa sumbernya itu sendiri.

Dari simpulan di atas disarankan bahwa penelitian yang berfokus pada bahasa Pijin dalam iklan di televisi Indonesia diharapkan dapat menjadi acuan dalam pembinaan bahasa, serta memberikan kontribusi dalam pengembangan teoretis dan metodologi pada bidang sosiolinguistik.

\section{Daftar Pustaka}

Beretha, N. S. (1999). Variasi Bahasa Inggris pada Kawasan Pariwisata di Bali. Jurnal Humaniora, 11(3), 122-131.

Chaer, A. dan Agustina, L. (2010). Sosiolinguistik. Jakarta: Rineka Cipta.

Choi, K. Y., \& Chong, S. L. (2017). Campur Aduk Bahasa Melayu dan Bahasa Cina. Journal of Modern Languages, 18(1), 56-66.

Hanafi, A. H. (2011). Metodologi Penelitian Bahasa. Jakarta: Diadit Media. 
Holmes, J. (2013). An Introduction to Sociolinguistic, Fourth Edition. New York: Routledge.

Palupi, D. H. \& Pambudi, T. S. (2006). Advertising that Sells. Jakarta: Gramedia Pustaka Utama.

Pastika, I. W. (2012). Bahasa Pijin dan Bahasa Kasar dalam Acara TV Indonesia. Jurnal E-UTAMA Jabatan Bahasa \& Kebudayaan Melayu. Singapura: Universiti Teknologi Nanyang.

Sugiyono. (2015). Metodologi Penelitian Pendidikan. Bandung: Alfabeta.

Suhardi, B. (2009). Pedoman Penelitian Sosiolinguistik. Jakarta: Pusat Bahasa Departemen Pendidikan Nasional.

Sukesti, R. (2015). Pendekatan Linguistik Sinkronis dan Diakronis pada Beberapa Dialek Melayu: Pemikiran Kritis atas Sejarah Bahasa Melayu. Jurnal Pendidikan Bahasa dan Sastra, 15(1), 46-56.

Sulaeman. A. (2017). Metode Penelitian Pendidikan. Tangerang: FKIP UMT Press.

Sulaeman. A. (2018). Sosiolinguistik. Tangerang: FKIP UMT Press.

Wardaugh, R. \& Fuller, J. M. (2015). An Introduction to Sociolinguistic, Seventh Edition. United Kingdom: Basil Blackwell Inc. 